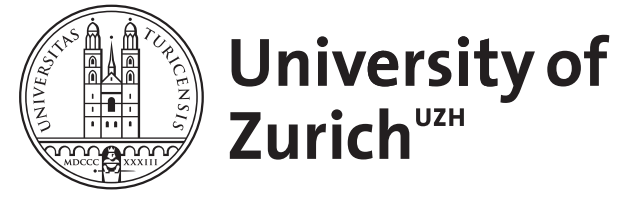

\title{
Drugs Boosting Conflict? A Micro-Level Test of the Linkage Between Substance Use and Violence
}

\author{
Hecker, Tobias ; Haer, Roos
}

DOI: https://doi.org/10.1080/09546553.2013.796935

Posted at the Zurich Open Repository and Archive, University of Zurich ZORA URL: https://doi.org/10.5167/uzh-115687

Journal Article

Accepted Version

Originally published at:

Hecker, Tobias; Haer, Roos (2015). Drugs Boosting Conflict? A Micro-Level Test of the Linkage Between Substance Use and Violence. Terrorism and Political Violence, 27(2):205-224.

DOI: https://doi.org/10.1080/09546553.2013.796935 


\title{
Terrorism and Political Violence (in press)
}

\section{Drugs Boosting Conflict? A Micro-Level Test of the Linkage between Substance Use and}

\section{Violence}

Tobias Hecker

Department of Psychology, University of Konstan₹, Germany.

Roos Haer (Corresponding author)

Department of Politics and Public Administration, University of Konstanz, Germany.

\section{Recommended citation:}

Hecker, T., \& Haer, R. (in press). Drugs boosting conflict? A micro-level test of the linkage between substance use and violence. Terrorism and Political Violence.

\begin{abstract}
Many studies have emphasized the role of natural resources in the onset and duration of armed conflict. Due to its characteristics, narcotics are considered to be one of the most influential resources. However, the dynamics of how this particular commodity is linked to conflict is still not well understood. Most scholars have focused on the revenue aspects of narcotics and only few have mentioned the micro-level aspect, i.e. the effect of drugs intake and alcohol consumption on combatant's behavior during the conflict. With the help of a dataset based on 224 interviews held with former combatants in the Democratic Republic of the Congo, we examined this latter dynamic. Our analyses show, after controlling for armed group-level and individual-level variables, that drug intake and alcohol consumption boost the amount of perpetrated violent actions by combatants.
\end{abstract}

Keywords; narcotics, conflict, drug, alcohol, violence

Words: 8.454

\section{Acknowledgement}

The Deutsche Forschungsgemeinschaft (DFG) and the non-governmental organization (NGO) victim's voice (vivo) international supported the research. We are grateful to all the former combatants for their readiness to participate and willingness to talk about often intimate and painful subjects. We also thank Dr. Lilli Banholzer, Désiré Muhire Biyonga, Ben Ombeni Cigolo, 
Prof. Dr. Thomas Elbert, Valentin Gold, Katharin Hermenau, Dr. Harald Hinkel, Prof. Dr. Katharina Holzinger, Flory Barhimanya Kahisa, Dr. Anna Maedl, Heike Riedke, Dr. Maggie Schauer, Penelope Summers, and Roger Buhendwa Zashurwa for their support, assistance with the data collection, and for help with logistics. Additionally, we want to thank the staff of the UN Demobilization camp and of the Tumaini Reintegration-Center in Goma.

\section{Introduction}

Natural resources have played a conspicuous role in the history of armed conflicts. Especially with the sharp drop in foreign assistance to many governments and non-state armed groups due to the end of the Cold War, belligerents have become more dependent upon mobilizing private sources of support to sustain their military and political activities. ${ }^{1}$ This search for finance defined a new political economy of war, in which armed conflict increasingly becomes the means to individual commercial ends: gaining access to valuable resources. ${ }^{2}$

The relationship between conflict and natural resources was first examined by Collier and Hoeffler. ${ }^{3,4}$ They found a strong relation between a state's reliance on the export of natural resources, and the likelihood it will suffer from civil war. Subsequently research has determined that the strength of this relationship is influenced by the type of natural resources, their illegal nature, their level of obstructability, and the nature of the conflict. ${ }^{5}$ Drugs, which are lootable, illegal, and not easily obstructable, are then also considered as one of the 'deadliest' natural resources available: they have been positively linked to conflict duration in diverse statistical studies as well as in more qualitative accounts. However, the way in which drugs interact with conflict is not well understood. ${ }^{6}$ Some authors have emphasized the revenue aspect, while other authors have suggested a more micro-level linkage: substance use play an important role in the combatant's behavior on the battlefield. It makes them more aggressive and violent and at the same time removes learned constraints against the use of violence, which in turn might increase the duration and/or boost the conflict.

Although difficult to test, most research has emphasized the revenue aspect of drugs, while neglecting this important micro-level interaction between drugs and conflict. This study will, therefore, investigate this latter mechanism. It is important to note, however, that we do not deny the existence of the revenue mechanism. Notwithstanding, we are of the opinion that the picture is more complicated than is portrayed so far in the literature. And gaining a better understanding of the entire set of dynamics that appear to be generating and sustaining a range of contemporary civil conflicts is necessary for anyone thinking of policy prescriptions that might facilitate a lasting peace. $^{7}$ 
In testing the linkage between drugs and conflict on a micro-level, we first start by providing an overview. In doing so, we show that little attention has been devoted to testing the causal mechanisms linking substance use to aggression and violence. Thereafter, we explain how we created the unique dataset based on recent interviews held in the eastern provinces of the Democratic Republic of the Congo (DRC) with combatants of different factions. During more than 200 intensive interviews, we have asked these recently demobilized fighters questions concerning their drug intake and alcohol consumption and their violent behavior during their time spend in the armed groups. Using this information, we statistically test this possible microlevel linkage between substance use and violent behavior. We conclude with a discussion of the results and how they should influence future research in this area.

\section{Theory}

In the current discussion on the determinants of civil war onsets, much attention is devoted to the relationship between economic incentives and armed conflict. Especially, after the end of the Cold War when armed movements could no longer rely on the financial support of the super powers, economic motivations have increasingly been blamed for action of belligerent parties on civil wars. ${ }^{8,9}$ Or as Grossman states, "in such insurrections the insurgents are indistinguishable from bandits or pirates". ${ }^{10}$ In particular, academic literature has centered on the role of natural resources, in overcoming this resource constraint and thereby influencing the nature of the conflict. Collier and Hoeffler were among the first who examined this possible relationship. ${ }^{11,12}$ In their pioneering cross-sectional studies they found that states that rely on the export of natural resources face a higher risk of civil war than resource-poor states. Subsequently research has offered some more detailed insights in the link between primary commodities and conflict. Fearon and Laitin, for example, who use a different data set, find that countries that export oil but not other types of primary commodities - are more likely to undergo a civil war. ${ }^{13}$ Other scholars have focused more on the differences between types of primary commodities. Lujala, for instance, shows that the lootability (or accessibility) of natural resources increases the feasibility of insurgency and lengthens the duration of a civil war. ${ }^{14}$ At the same time, she shows that these lootable resources (such as secondary diamonds and gemstones) have no link to conflict initiation. An important contribution in this tradition is also made by Ross. ${ }^{15} \mathrm{He}$ concludes from a study of 15 cases that the level to which a commodity is linked to conflict depends on its lootability, obstructability, and legality.

Taking this research into account, drugs can be considered as one of the most troublesome resources. ${ }^{16}$ Drugs, like opium, marijuana, and coca leaves, are a lootable resource. They have a 
high monetary value but are compact and easy to appropriate, store, and transport, thereby proving to be convenient financial resources for armed groups. ${ }^{17,}{ }^{18}$ Unlike timber and oil, drugs are not easily obstructable (there is no need for a complicated enterprise to cultivate it); they require little control over infrastructure or time to process, which enhances exploitation. Additionally, the illegality of drugs also makes them benefit insurgents disproportionally, because they are less susceptible to be influenced by international prohibition regimes. ${ }^{19,} 20,21$ Notwithstanding, it is surprising that compared to other commodities, such as oil and gemstones, few studies have focused on the linkage between drugs and conflict. This relative lack of research might be due to the fact that the dynamics between drugs and conflict are presently not too well understood. ${ }^{22}$

Most authors emphasize the revenue aspect of drugs, when linking it with conflict. The trade in illegal drugs generates enormous revenues for armed groups that can be used, for example, to recruit and pay members, to acquire weapons, to establish command bases, to forge alliances with other armed groups and, ultimately, to become more effective and deadly. ${ }^{23,24}$ The study of Holmes, Gutierrez de Pineres, and Curtin is an example of this focus. ${ }^{25}$ They show in their examination of the relationship between coca production and Colombian guerilla violence that coca eradication, measured in hectares, is positively and significantly correlated with leftist guerrilla violence. However, the mere presence of coca cultivation (measured in hectares in cultivation even after eradication efforts) is insignificant. Also Piazza confirms that drugs, in the form of opium, is an important driver for conflict and violence. ${ }^{26}$ He concludes that Afghanistan's provinces that feature opium cultivation are at a significantly higher risk of experiencing terrorist attacks and of seeing their citizens harmed in terrorist incidents than provinces that do not cultivate opium. Illicit drug markets are then also considered to be a crucial contributor to terrorism because they finance the existence and survival of the Taliban and $\mathrm{Al}$ Qaeda.

Besides these impressive examples of case studies on the linkage between drug production and/or drug cultivation and conflict (in whatever form), more cross-sectional and time-series studies also explore this revenue aspect. Fjelde and Nilsson for example, examine the variation in interrebel violence and state that this kind of violence should be higher in civil wars where the rebel organizations can fund their struggle through the sale of valuable natural resources. ${ }^{27}$ They show in their analyses that drugs production, in contrast to gemstone production, is significantly related to this particular form of violence. However, these results remain tentative. Some other studies, however, do not show a clear linkage between drug cultivation, its theorized revenue, and conflict. For example, Buhaug, Gates and Lujala in their study on the variation of civil conflict 
duration, show that gemstones and petroleum production in conflict areas prolong conflict duration, but that drug is not related to civil conflict duration. ${ }^{28}$ In some of their models, drugs have even the opposite effect of what was expected. Also Wood showed in his quantitative analysis on rebel violence that the presence of gemstones or drugs in the conflict zone is statistically unrelated to the level of rebel violence against the civilian population. ${ }^{29}$

These mixed results indicate that testing the revenue aspect of drugs and how this aspect influences conflict is challenging. Not only, are the number of countries involved in large-scale production of opium and coca low (drugs is a rare commodity), but obtaining reliable data on drug cultivation and production across time and space presents an additional problem for reliable statistical analysis. Additionally, it seems as if these different results are due to the various operationalization of the term 'conflict': some studies are focused on civil war duration, others on civilian killings or on interrebel violence. Furthermore, the production of drugs and conflict might reinforce itself. Lind, Moene, and Willumsen for example, state that the conflict in Afghanistan creates new illegal poppy cultivation opportunities since the state is not able to induce a regime of tight control. ${ }^{30}$ Consequently, some scholars (although not denying the revenue dynamics of drugs per se) have focused more on the individual level when researching how drugs relate to conflict and violence. In other words, they are examining whether substance use influence violent behavior. As such, they leave the idea of 'selling drugs', 'drugs cultivation', and concepts such as 'revenue'. Instead, they look at the effect of drugs on combatant's behavior.

There are some preliminary indications that the use of drugs influences behavior in a negative sense. First, there is some anecdotal evidence given by the combatants themselves that indicates that substance use removes learned constraints against violence and incites aggression and violence. A Congolese captain, cited by Baaz and Stern explained: "War is crazy, it destroys the minds of people. Some people just go crazy. ${ }^{31}$ Rape is a result of that too, especially the bad rapes. Also, a lot is because of drugs. If you take drugs, drink, or other things - it is not good. And many, many...most take drugs." Also in our interviews, former fighters emphasized the linkage between drugs and violence. Participant (2080) explained: "In Mai-Mai Janvier [officially called Alliance des Patriotes pour un Congo Libre et Souveraine], they smoked marijuana. When they smoked, they were eager to go fighting. But when they did not smoke, they were lazy", 32 Also former combatant (2054) told us: "As a soldier I took a lot of drugs. I was drinking beer, smoking marijuana and sniffing petrol. Drugs help you to have no fear and just to shoot. In the CNDP [Congrés National pour la Défense du Peuple] we raped a lot of women. Soldiers rape, because they get out of control from smoking all this marijuana." 
In academic research, and especially in the field of political science, drugs usage is often linked to discipline problems in the armed groups. Ross for example, argues that drugs as a lootable resource, create opportunities for soldiers of all ranks to earn money by extracting or transporting the resources themselves, or extorting money from others who do. ${ }^{33}$ This results in a reduced level of discipline and central control within the armed group that controls the resources. These problems are not only likely to lengthen conflicts by making it harder for commanding officers to impose the terms of a settlement on their own forces, but more importantly, discipline problems, have in turn, been positively linked to civilian abuse. Humphreys and Weinstein showed, for instance, in their analysis of Sierra Leonean factions that the higher level of indiscipline permitted inside the armed factions, the greater the perpetrated abuses outside the faction. ${ }^{34}$ This is also confirmed by Weinstein. ${ }^{35}$ He argues that a rebel group's access to easily accruable income, for example, from lootable natural resources such as drugs, are central in shaping the organizational structure of the movement and its strategies regarding treatment of noncombatants: it makes the organization more violent.

Furthermore, some other studies in the field of psychology give additional insights in the linkage between substance use and violent behavior. However, the connection between substance use and violent behavior is complex and is suggestive rather than conclusive. ${ }^{36}$ Overall, these more psychological studies suggest a direct link between substance use and violent behavior. Substances decrease the threshold of using violence, i.e. it removes the learned constraints. At the same time, particular substances seem to incite violence directly via aggression and rage.

Although the reviewed macro-level studies have focused mostly on the impact of drugs such as marijuana and cocaine, in the field of psychology, alcohol is most often connected to violence and aggression. Although alcohol is legal in many countries, it is the most common and perhaps influential drug available. It is, for instance, estimated that close to $4 \%$ of all deaths globally are attributed to alcohol consumption. ${ }^{37,38}$ Research indicates that the most commonly accepted mechanism for alcohol-induced aggression is through the disinhibition of fear via anxiolytic action. ${ }^{39}$ For example, alcohol can affect cognitive function in such a way as to decrease the capacity to plan actions in response to threatening situations. Alcohol may also increase the perception of pain as a cause of greater defensive aggression. ${ }^{40}$ Additionally, alcohol may also serve as a triggering mechanism to instigate aggressive acts for those who already have violent propensity and find themselves in "aggressive" situations. ${ }^{41}$

Although alcohol is clearly the drug with the most evidence to support a intoxicationviolence relationship, studies have also found a relationship between physical aggression and drugs use, although the results are less robust. ${ }^{42}$ The association between cocaine use and physical 
aggression is one of the relations that is well established. ${ }^{43,44,45}$ Less is known, however, about the association between violence and marijuana use. ${ }^{46}$ The use of cannabis is widely perceived by recreational users as a harmless drug, a view fostered by some sections of the press and even (surprisingly) by a leading medical journal. ${ }^{47}$ Cannabis in most recreational settings decreases aggressive feelings in humans and increase sociability. However, no drug is without unwanted effects. For example marijuana use may also remove learned constraints against violence and thus may incite aggressive and violent behavior. Furthermore, research has shown that predisposed individuals (those that suffer from psychiatric illnesses such as schizophrenia or who have preexisting antisocial personality traits), especially if under stress, become aggressive after taking cannabis. ${ }^{48}$ There is also some evidence that chronic use of marijuana can eventually alter the nervous system in a way that disrupts social communications; an effect that may increase one's involvement in altercations that escalate to violence. ${ }^{49}$ Furthermore, its abuse is also connected to crimes of violence, although there are relatively few sources of data on patterns of illicit drug use and violence. ${ }^{50}$ For example, Spunt et al. show that marijuana was often used in the 24-hour period before homicide. ${ }^{51}$ All in all, these studies reveal somehow mixed or contradictory findings concerning the link between marijuana intoxication and aggressive behavior or violence ${ }^{53}$ but we can conclude that under certain circumstances marijuana consumption seem to lower the threshold for aggressive and violent behavior.

Notwithstanding, if substance use caused violence only by making individuals behave more aggressively, violence would be equally common in all places where drinking and drug consumption occurs. Consequently, it is important to note that substance use operates in environmental, social, situational, and cultural context that influence the potential for violent outcomes. $^{54,55}$ Additionally, it is important to note that substance use affects individuals differently, based on their physiology, psychology, history, gender, and other personal and cultural factors. For example, drug use may interact with an individual's personality or temperament characteristics, such as impulsivity and hyperactivity, to increase the risk of offensive commission. ${ }^{56}$ Researchers have found then also difficult to cut through these complexities to specify the particular effects of alcohol and drugs on violence. ${ }^{57}$

Besides the anecdotal evidence, the indirect linkages between drugs and violence as identified in the field of political science, and the partly confirmatory studies in the field of psychology, few studies have examined the relationship between substance use and violence perpetrated on the battlefield. This is surprising because this linkage is often suggested. Some authors, for instance, consider hallucinatory drug intake a critical factor that has contributed to the desensitization of soldiers during their prolonged exposure to violent aggression and that has prepared them for 
combat. ${ }^{49}$ Maclure and Denov, focusing on child soldiers, state for example, that the abundant use of alcohol and hallucinatory drugs unquestionably contributed to the desensitization of children and their transition from disoriented and highly impressionable youngsters into effective combatants. ${ }^{50}$ However, this linkage has never been empirically tested. In the following section, we attempt to fill this scientific niche.

\section{Research Design}

Testing the micro-level linkage between substance use and combat action requires disaggregated quantitative data. This study employs, therefore, information retrieved from systematic interviews with former combatants that were active in the DRC. The history of this country has been one of civil war and violence. After independence in 1960, unrest and rebellion plagued the country, until 1965, when Mobutu seized control of the country and declared himself president. Under his rule, the country, then called Zaire, became a dictatorship that came to an end when Kabila, backed by Rwanda and Uganda, captured the capital and removed Mobutu from office in 1996. Nonetheless, Congo's troubles continued. A rift between Kabila and his former allies sparked a new rebellion. Angola, Namibia and Zimbabwe took Kabila's side against Rwanda and Uganda's influence in the DRC, turning the country into a vast battleground for many years. In 2003, an official peace agreement was signed. Notwithstanding, the eastern provinces of the DRC are still the site of one of the world's worst on-going humanitarian crises and many warring factions are still straying through large areas of the country, raiding villages and committing severe human right abuses. ${ }^{51}$

The data used to explore the micro-level linkage was collected between March and May 2011 in Goma, the capital of the North Kivu province in the eastern part of Congo. During this period, 224 former combatants were interviewed ( 2 women and 222 men) with the help of locally trained translators. ${ }^{52}$ Since $25 \%$ of all the interviewed former fighters were originally from Rwanda, these translators had to be able to speak Kinyarwanda besides Kiswahili. The former combatants were on average 24 years old at the time of the interview (with a minimum of 13 and a maximum of 50), and had 5 years of formal education (with a minimum of 0 and a maximum of 14 years). In total, $72 \%$ of the semi-structured interviews took place at the demobilization camp of the United Nations, $27 \%$ were conducted at a vocational training center for war-affected youth, and only $1 \%$ of the interviews took place at the military detention facility. The demobilization camp is a transition camp for all combatants who leave any armed groups in the province of North Kivu. Participants, however, stayed only between 20 and 72 hours in the 
demobilization camp before being sent to other places. In 8 cases, this led to the preliminary termination of the interview. Consequently, they were removed from the analysis.

Participants belonged to a variety of armed groups and forces. Most of them belonged to the different Maï-Maï groups (74\%), followed by the Forces Démocratiques pour la Libération du Rwanda (FDLR) (38\%), the Congrés National pour la Défense du Peuple (CNDP) (9\%), the National Army Forces Armées de la République Démocratique du Congo (FARDC) (5\%), the Rassemblement Congolais pour la Démocratie (RCD) (3\%), and some other smaller armed groups such as the Rwandan Armed Forces from before 1994.

The Ethical Review Board of the University of Konstanz approved the study and the United Nations and the respective Congolese nongovernmental non-profit organization allowed us to interview all participants enrolled in their program. All participants gave their informed consent orally after explaining to them that they could refuse to answer questions, stop the interview at any time, and that there were no negative consequences for them when they did so. Additionally, we guaranteed that we would use the given information only for scientific purposes and that we would never reveal their identity. In addition to the oral consent of the participants, we asked the respective institutions for permission to interview underage former child soldiers, as their caregivers were not available. Participants received financial compensation of about 2 U.S. dollars.

\section{Operationalization}

\section{Dependent variable: Perpetrated Violence}

Capturing the amount of perpetrated violence by a former combatant during his or her time in the armed group is challenging. Often, former combatants cannot remember the exact number of combat actions they were involved in since their memory is distorted due to trauma related sufferings, e.g. posttraumatic stress disorder. ${ }^{53,54}$ Consequently, asking about frequency results in an unreliable measure. However, previous research indicated that former combatants remember the different types of violence they perpetrate. ${ }^{55} \mathrm{We}$, therefore, captured perpetrated violence with the help of seven questions concerning self-committed violence types: (1) Have you ever severely injured or mutilated someone?; (2) Have you killed someone?; (3) Have you ever attacked a village or settlement?; (4) Have you ever physically assaulted someone (e.g. beat, hit or slapped)?; (5) Have you ever physically assaulted someone with a weapon?; (6) Have you ever sexually assaulted someone (e.g. touched the private parts, vaginal or anal rape or introduced object in any part of the body)?; and (7) Have you ever participated in a massacre (i.e. killing a 
group of civilians)? Each offense type was coded as committed (coded as 1) or not committed (coded as 0 ). With these answers, a simple additive index was built capturing the total sum scores per former combatant, running from 0 (indicating that the former combatant did not participate in many violent events) to 7 (indicating that the former combatant was active in all types of violent events). The Cronbach's alpha coefficient, measuring the internal consistency or reliability of this measure, is 0.76 , meaning that the different questions are significantly related to each other and were suitable for building this index. ${ }^{56}$ The interviewed former combatants perpetrated on average 4 of these violent actions, with some (15 former combatants) perpetrating none and others (13 former combatants) a maximum of 7 . Table 1 shows more descriptive statistics of this measure.

\section{Independent and control variables}

\section{Narcotic usage}

To measure the narcotic usage of the former combatants, we asked them several questions. First, we asked them whether they have taken drugs in the last four weeks (coded 0 if no and 1 if yes). We purposefully gave them this time frame, to enhance their memory. On this question, $17 \%$ of the former combatants indicated to have consumed drugs (drug use). Marijuana and a hallucinogenic drug plant called "36 oiseaux" (translated: 36 birds) were mostly used. These drugs have been available in all armed groups and were used throughout the day. Most former combatants indicated to especially have taken drugs before going to combat (34\%) and only a few (4\%) stated to have taken drugs right after fighting. This shows that only a few former combatants in our sample consider drugs as a self-medication against trauma-related disorders due to combat experience.

Measuring the quantity of the drug intake is problematic, due to the different formats and different ways of using it. We, instead, measured whether the drugs caused any problems by asking the former combatants, if their drug consumption caused any problems with their family, at work, and/or with the law (drug functioning). The question was coded 0 if the combatant indicated not to have encountered any problems and 1 if he or she did. On average, $82 \%$ of the former combatants indicated to have suffered from some problems in functioning due to the intake of drugs. Table 1 shows more descriptive statistics of these two drugs measures.

Besides our focus on drug intake, we asked some additional questions concerning the consumption of alcohol. We asked the former combatants, whether they have used alcohol (alcohol use) in the last four weeks (coded 0 if no, coded 1 if yes). From the 223 former combatants, who answered this question, 53\% indicated that they drank alcohol in the previous 
four weeks. Most of them drank beer or banana beer (35\%) or hard liquor including liquor that they brew at home (17\%). We also asked to what extent the consumption of alcohol caused any (occupational, family, and health) problems for the respondent (alcohol functioning; coded 0 if no and 1 if yes). Less than $20 \%$ indicated to have suffered from these kinds of problems due to alcohol consumption. Table 1 shows more descriptive statistics of these measures.

\section{Voluntary or abducted}

A possible intervening variable that might influence the level of perpetrated violence is whether the former combatant joined on a voluntarily basis or was abducted into the armed group. Although the decision to join is in some cases the result of limited and equally harsh choices in a resource poor region of instability, voluntary combatants might feel more in control of their lives and might perceive the armed group as less threatening than forcibly recruited combatants would. ${ }^{57,58}$ It is then also highly likely that those former combatants that were abducted are less willing to cross personal boundaries by perpetrating violence. To control for this, we included a measure capturing this (coded 0 if abducted, and 1 if the combatant joined voluntarily). This measure shows that $51 \%$ of the former combatants have been abducted into their first armed group. Table 1 shows more descriptive statistics of this measure.

\section{Age joined}

Previous research has also indicated that the amount of perpetrated violence depends on the age of the former combatant at the time of joining. ${ }^{59}$ Some authors, for example, suggest that children may be more willing to fight for honor or duty, for revenge or for protection from violence. ${ }^{60,61}$ Also Schauer and Elbert state that children are easier to retain in the group because they are more malleable and adaptable, and hence easier to indoctrinate. ${ }^{62}$ They stick more to authorities without questioning them. Additionally, moral and personality development is not yet completed in children, reducing their inhibition against performing crimes against humanity. To control for this possible effect, we included a variable measuring the age of the former combatant at the time of joining (voluntarily or were abducted into). On average the former combatants were 17 years old when they joined. Some were born in the group (coded as being 0 years old when joining) and others were recruited much later in their life. See Table 1 for the descriptive statistics.

Duration in armed group 
The duration a combatant spends in the armed group, might have a profound impact on the amount of violence that he or she perpetrates. Especially the initial period of staying within the armed group is often characterized by extensive forms of violence. New combatants are almost always subjected to harsh life-threatening initiation procedures, such as severe beatings, forced killings, magic-spiritual rituals (e.g. tattooing, scarring, spraying with blood or 'holy' water), and forced drug intake, in order to make them 'proper soldiers' and fear the repercussions of escape. ${ }^{63}$ To control for this possible effect, we included a variable measuring the total duration in an armed group in years. On average a combatant stayed more than 6.5 years, with one former combatant staying 28 years and another for not more than 2 weeks ( 0.04 years). See again Table 1 for more descriptive statistics.

\section{Number of groups}

The amount of perpetrated violent actions might also depend on the number of armed groups the former combatant was active in. We, therefore, asked the former combatants to tell us in how many armed groups they served. On average a former combatant was a member of 1.5 armed groups, with a maximum of 5 armed groups. Table 1 shows more descriptive statistics of this measure.

\section{$\underline{\text { Rank }}$}

Another possible influential variable is the rank of the combatants. Some initial research showed that combatants with a higher position have perpetrated more violence compared to those without a rank. ${ }^{64}$ To account for this possible effect, we included in the analyses a variable measuring the highest received military rank of the combatant. Only 18 combatants indicated not to have received any ranks at all. On average, combatants received the rank of sergeant. Three former combatants received the rank of colonel, which is also the highest rank in our sample. See Table 1 for more descriptive statistics.

\section{FDLR}

The last control variable we included in the analyses is one capturing the number of times a former combatant was a member of the FDLR. This group is particular known for their extremely cruel behavior on the battlefield. Romkema, for instance, states that "the FDLR is undoubtedly among the worst human rights violators in the North and South Kivu provinces" and that "the FDLR has beyond any doubt the largest and most negative impact on local communities". ${ }^{65}$ Since we do not possess any information on how long a former combatant was a 
member of a particular armed group, we attempt to control for this effect by counting the number of times a former combatant was a member of the FDLR. The variable ranged from 0 to 2 , and has an average of .5. See Table 1 for more statistics.

Table 1 about here

\section{Results}

Before presenting the multivariate analyses, we show some descriptive statistics that gives more insight in the influences of drug intake on the combatants' emotional state. To capture the effect of substance use on the emotional state, we described to the former combatants some possible effects of drugs intake. For instance, we asked whether they felt powerful or mighty after they took the drugs or whether they the drugs took away pain and fear. The former combatants could agree or disagree with these statements. Figure 1 presents these results.

Figure 1 about here

Figure 1 shows the percentage of combatants acknowledging that taking drugs has a particular effect. Although, these descriptive statistics only focus on drugs intake and not on alcohol, they give a first insight in a possible relationship between the usage of drugs and violent behavior. The figure shows that most combatants felt no fear, more powerful and more aggressive after drugs consumption. In contrast, only few former fighters indicated that the intake of drug made them calm, made them hallucinate and made them feel no pain. This coincides with the results of the previous mentioned research that links drugs to aggressive behavior.

We performed several multivariate linear regression analyses to statistical confirm these descriptive results. None of the calculated models suffered from multicollinearity. Additionally, we calculated the models with all theoretically possible interaction variables. However, none of these interaction variables were statistically significant. Besides these models, we have additionally calculated every model with an ordered logit regression. However, no significant different results between these two methods could be detected. Table 2 shows the regression analyses with the usage of alcohol as the dependent variable. 
Table 2 about here

The first model in Table 2 shows the relationship between alcohol consumption and the perpetrated violence by the former combatants. This model only takes into account whether they have used alcohol in the last four weeks or not. Whether this consumption caused any problems in functioning is tested in the second model of the table. As the first model shows, there is a highly statistically significant relationship between their alcohol consumption and their level of perpetrated violence (coefficient of 0.653).

Most of the control variables are also highly statistically significant. The negative coefficient of -0.103 indicates that the younger the combatant, the more likely they have perpetrated a larger amount of different violent types. This result is also confirmed by other research, indicating that young combatants are more inclined to be aggressive and violent on the battlefield. ${ }^{66,67}$ The effect of the duration variable is also statistically significant. The negative coefficient of -0.050 indicates that the shorter a combatant stayed with the armed group, the more different forms of violence he or she has perpetrated. This negative relation disconfirms our initial idea. However, although statistically significant due to the large sample size, the effect size is rather small. Therefore, we are reluctant to draw any strong conclusions about the influence of this variable on the level of perpetrated violence.

Military rank and recruitment also have an important effect; the higher their military rank, the more likely a former combatant has perpetrated different violence types. Furthermore, those fighters that joined voluntarily are more likely to perpetrate more different forms of violence than those that were abducted. This latter result is confirmed by a study conducted by Hecker et al. ${ }^{68}$ In their study on the impact of perpetrated violence on the mental health of the combatant, they found that those combatants that joined voluntarily reported more perpetrated violence types than forcibly recruited combatants.

The second model is looking at whether those combatants who indicated that they have problems functioning due to their alcohol usage perpetrate more violence. The positive and statistically significant coefficient of 0.735 indeed confirms this idea. Those former combatants that endured more problems due to their alcohol usage perpetrate more violence than those who did not suffer from these problems. The direction and strength of all other control variables remain robust in this particular model. Like in the previous model, however, the number of 
armed groups from which the former combatants where a member of, has no significant influence on the level of perpetrated violence.

The third and fourth models are the same as the previous two models. However, we included one extra variable, controlling for the membership of the FDLR. Due to this variable, the adjusted R-square increased in both models. In both models, membership of the FDLR has a positive influence on the level of perpetrated violence, i.e. those former combatants that were a member of this particular armed group perpetrate more different forms of violence than those who are not a member of this particular group. These results validate our survey data by confirming the destructive role of the FDLR in the Congolese conflict.

In the last model, i.e. the full model, all main variables are included that are statistically significant in the previous models. Since the two alcohol variables, measuring alcohol usage and possible problems in functioning due to this usage, are correlated with each other, we decided to focus on the one measuring the functioning of the former combatants, since its effect is somewhat stronger. As can be seen from Table 2, no significant changes could be detected and the effect of the variables remains robust. In addition, the adjusted R-square, measuring the explained variance, is consistent with all the other models.

Table 3 shows the results of the multivariate regression analyses focused on drug consumption. It is important to note that it is highly likely that the presented effects are underestimated. Not only was the intake of drugs strictly forbidden in the different demobilization camps, but also because certain drugs are not recognized. This is especially the case for members of the different Maï-Maï factions. These factions are known for their rituals and adherence to magical-religious practices that protect combatants during battle and help them fight. ${ }^{69}$ One of these practices is the intake of a mixture of local hallucinating plants by cutting themselves and placing the mixture of plants directly in the blood stream before going to combat. However, this is considered to be a 'traditional medicine' rather than a drug.

Additionally, in certain armed groups, such as in the FDLR, the consumption of drugs by their members is strictly forbidden. However, our data show that although forbidden, from the 98 former FDLR combatants (those combatants that were a member of the FDLR before they got demobilized) in our sample, 18 said to have taken drugs in the last four weeks. This is not surprising, considering the fact that the FDLR is heavily involved in the production and distribution of drug (at least in the territory of Uvira). ${ }^{70}$ This is confirmed by one of the interviewed former combatants (participant 2087), who told us: “They [the FDLR] took people's fields by force and turned them into marijuana fields. Now they sell it and earn a lot of money." 
Also another participant (2069) confirms: "The FDLR grows marihuana in places like Masisi or Kimua. It is their business."

The first model in Table 3, confirms the idea of what some of the former combatants (for instance former combatant 2092) told us already: "When soldiers smoke marijuana, they cause trouble. They start to fight and you have to watch them so that they do not run away and rape." The highly significant coefficient of 0.796 indeed shows that those former combatants that admitted to having taken drugs in the previous four weeks were more likely to perpetrate more types of violent actions. Drugs in this sense seem to remove the learned constrains against violence. Additionally, all the other control variables have the same direction as for alcohol use: those former combatants that joined when they were younger perpetrate more violence, those that joined voluntarily are more violent than those that were abducted, and those having a higher rank have perpetrated more types of violent actions than those that have a lower rank. And again, the number of armed groups of the former combatants does not play any statistically significant role.

Table 3 about here

The result presented in the second model is more surprising. Those former combatants indicated that they suffered from problems due to their drug intake are less likely to have perpetrated types of violent acts than former combatants that did not indicate to suffering from problems due to consumption of drug. Although this variable is not significant related to the perpetrated violent actions, it is worth noting that this negative effect is probably due not only to the small number of observations, but also to the fact that those who indicated to have suffered from problems related to drug use are probably heavy drug users and abusers. It is, therefore, highly likely that their drug consumption interferes with their normal daily functioning, i.e. they could not fulfill their duties as soldiers within the armed groups. Consequently, there are likely to be less involved in combat and have stayed more often in military detention. We see a first indication of this mechanism when comparing the average perpetrated amount of violence types between those that have indicated to suffer from problem due to drugs intake (average of 4.25) to those that did not seem to encounter any problems (average of 4.88). However, due to a limited amount of observations and a skewed distribution across these two groups of former combatants, it is not possible to test whether this difference is statistically significant. Future research should then also 
investigate this more in depth. Also many of the control variables, previously statistically significant and robust, turned out to have no effect on the level of perpetrated violent actions. The only variable that remains robust is the age of the former combatants when they joined or were abducted into the armed group for the first time. It is not surprising that the adjusted Rsquare is low.

Again, we added the control variable measuring the membership rate of the FDLR in the third and fourth model. The adjusted R-square increased significantly in these models and the positive and statistically significant coefficient of 0.383 and 0.986 indicate that those former combatants that were a member of the FDLR perpetrate more violent types than those that were not a member of the FDLR. Adding this particular control variable increased not only the adjusted R-square but also strengthen the effect of military rank and recruitment method (joining voluntarily or getting abducted into the armed group) on the different perpetrated types of violent actions.

In the last model of Table 3, we included all the major statically significant variables. The conclusion remains robust in comparison to the first and third model: those former combatants that admitted to have used drugs in the last four weeks have likely perpetrated more violent actions.

Although the literature on substance use has treated alcohol and drugs often as separated substances that are differently linked to violence and aggressive behavior, we show in Figure 2 the full model with the $95 \%$ confidence interval level. In this model we combine drug use and alcohol use together with all the robust control variables. We have focused on these two particular variables, since drug functioning is insignificant and since this combination results in the most observations. The figure shows that all of the pictured variables are at least significant at the $5 \%$ confidence interval: none of the variables crosses the null line. Both drugs intake as well as alcohol consumption is positively related to the amount of perpetrated violence. However, the influence of drugs on the perpetrated types of violence is somewhat higher.

Figure 2 about here

All the control variables are statistically significant: younger combatants are more violent, those with a higher rank perpetrate more violence, and lastly, those that joined on a voluntarily basis are 
more violent. Again, this model shows that the influence of both drug intake and alcohol use remains robust across models.

\section{Conclusion}

Most scholars examining the link between drugs and conflict have focused on the revenue dynamic linking these two concepts. Selling drugs give armed groups the means to prolong the conflict by allowing them to buy, for example, weapons and to attract recruits. However, few scholars have focused on another possible ongoing dynamic, i.e. how drugs intake is related to the combatant's behavior on the battlefield. With a unique dataset based on 224 interviews held with former combatants in the DRC, we tested this possible linkage. Our analyses show that alcohol and drugs consumption are highly related to the different types of violent actions the combatants perpetrated in the armed groups. These results remain robust after controlling for other possible individual and group explanations.

There are, however, some important limitations to this study. Although, we interviewed many combatants from different armed groups and forces, they were selected on a non-random basis. It is, therefore, highly likely that those combatants that are very aggressive and violent or have preexisting violent tendencies are still active in the different armed groups. Consequently, the real effect of drugs on violent behavior might be underestimated by our calculated models. Additionally, there is the question concerning the generalizability of our results. Future research should indicate whether the linkage between substance use and perpetrated violence is also present when interviewing combatants in different conflict settings. Notwithstanding, this study is the first attempt to examine the drugs-conflict nexus on a micro-level.

It is also important to note that we do not consider the use of alcohol or other drugs as a cause of violence. However, the analyses show that substance use boosts the likelihood of violence in the context of armed conflict. Both alcohol as well as drugs, such as marijuana, impair judgment and reason and reduce inhibitions. This is also confirmed by many combatants themselves that indicate that they often are intoxicated before going to battle. Hence, the widespread use of alcohol and drugs, while not the sole explanation, surely contributes to the high level of committed violence. We also think it is important that after the war, international and non-governmental organisations should address the impact of drugs on the former combatant adequately. Demobilization programs should be set up, which include assistance for alcohol and drug addiction for these soldiers. Only then we can decrease the likelihood of reoutbreak of violence. 


\section{Notes}

1. Philippe Le Billon, "The Political Ecology of War: Natural Resources and Armed Conflict," Political Geography 20 (2001): 561-584.

2. David Keen, The Economic Functions of Violence in Civil Wars (London: Oxford University Press for the International Institute for Strategic Studies).

3. Paul Collier and Anke Hoeffler, "On Economic Causes of Civil War," Oxford Economic Papers 50, no. 4 (1998): 563-573.

4. Paul Collier and Anke Hoeffler, "Greed and Grievance in Civil War," Oxford Economic Papers 56, no. 4 (2004): 563-95.

5. See among others Michael L. Ross, "Oil, Drugs, and Diamonds: the varying Roles of Natural Resources in Civil War," In Karen Ballentine and Jake Sherman (eds.), The Political Economy of Armed Conflict; beyond Greed and Grievance (Boulder: Lynne Rienner Publishers, 2003), 47 70.

6. Sven E. Cornell, "Narcotics and Armed Conflict: Interaction and Implications," Studies in Conflict \& Terrorism 30 (2007): 207-227.

7. David Keen, "Incentives and Disincentives for Violence," in Mats Berdal and David M. Malone (eds.), Greed and Grievance: economic agendas in civil wars (Boulder: Lynne Rienner Publishers, 2000) 19-41.

8. Cornell (see note 6 above).

9. James A. Piazza, "The Opium Trade and Patterns of Terrorism in the Provinces of Afghanistan: An Empirical Analysis," Terrorism and Political Violence 24 (2012): 213-234.

10. Grossman, Herschel I. Grossman, "Kleptocracy and Revolutions," Oxford Economic Papers 51, no. 2, (1999): 267-83 (p. 269).

11. Collier and Hoeffler (see note 3 above).

12. Collier and Hoeffler (see note 4 above).

13. James D. Fearon and David D. Laitin, "Ethnicity, Insurgency, and Civil War," American Political Science Review 97, no. 1 (2003): 75-90.

14. Päiv Lujala, "The Spoils of Nature: Armed Civil Conflict and Rebel Access to Natural Resources," Journal of Peace Research 47, no. 1(2010): 15-28

15. Ross (see note 5 above).

16. Ibid., 66.

17. Piazza (see note 9 above), 216

18. Cornell (see note 6 above). 
19. Note, however, that by focusing on the illegality of narcotics, some authors have neglected the impact of alcohol on conflict.

20. Cornell (see note 6 above), 209-210.

21. Piazza (see note 9 above).

22. Cornell (see note 6 above), 208

23. Of course, there are also indirect effects of narcotics; they can foster, for example, an environment favourable for domestic criminal activity, which erodes the authority of the state (see for example, Piazza (note 9 above) account on the Afghan war).

24. Piazza (note 9 above).

25. Jennifer S. Holmes, Sheila Amin Gutierrez de Pineres, and Kevin M. Curtin, "Drugs, Violence and Development in Colombia: A Department Level Analysis," Latin American Politics and Society 48, no. 3 (2006): 157-184.

26. Piazza (note 9 above).

27. Hanne Fjelde and Desirée Nilsson, "Rebels against Rebels: Explaining Violence between Rebel Groups," Journal of Conflict Resolution 56, no. 4 (2012): 604-628.

28. Halvard Buhaug, Scott Gates, Päivi Lujala, "Geography, Rebel Capability, and the Duration of Civil Conflict," Journal of Conflict Resolution 53, no. 4 (2009): 544-569.

29. Reed M. Wood, "Rebel capability and strategic violence against civilians," Journal of Peace Research 47, no. 5 (2010): 601-614.

30. Jo Thori Lind, Karl Ove Moene, and Frederik Willumsen, "Opium for the masses? Conflict-Induced narcotics production in Afghanistan," Working Paper, University of Oslo (2012).

31. Maria Eriksson Baaz and Maria Stern, "Making sense of violence: voices of soldiers in the Congo (DRC)," The Journal of Modern African Studies 46, no. 1 (2008): 57-86 (p. 78).

32. Due to security and privacy reasons all the interviewed former combatant's names throughout this paper are replaced by a number combination.

33. Ross (see note 5), 58.

34. Macartan Humphreys and Jeremy M. Weinstein, "Handling and Manhandling Civilians in Civil War," American Political Science Review 100, no. 3 (2006): 429-447.

35. Jeremy M. Weinstein, Inside rebellion. The Politics of Insurgent Violence (Cambridge: Cambridge University Press).

36. Sharon M. Boles and Karen Miotto, "Substance abuse and violence. A review of the literature," Aggression and Violent Behavior 8, no. 2 (2003):155-174. 
37. Jürgen Rehm, Colin Mathers, Svetlana Popova, Montarat Thavorncharoensap, Yot Teerawattananon, Jayadeep Patra, "Global burden of disease and injury and economic cost attributable to alcohol use and alcohol-use disorders," Lancet 373, no. 9682 (2009): 2223-2233.

38. Nadine Ezard, "Substances use among populations displaced by conflict: a literature review," Disasters 36, no. 3 (2012): 533-557 (p. 534).

39. Rick Lavine, "Psychopharmacological treatment of aggression and violence in the substance using population," Journal of Psychoactive Drugs 29, no. 4 (1997): 321-329.

40. Boles and Miotto (note 36 above).

41. Maurice P. Feldman, Criminal behavior: a psychological analysis (London: Wiley, 1977).

42. Peter N. Hoaken and Sherry H. Stewart, "Drugs of abuse and the elicitation of human aggressive behavior," Addictive Behaviors 28 (2003): 1522-1554.

43. Scott Macdonald, Kristin Anglin-Bodrug, Robert E. Mann, Patricia Erickson, Andrew Hathaway, Mary Chipman, Margaret Rylett, "Injury risk associated with cannabis and cocaine use," Drug and Alcohol Dependence 72, no. 2 (2003): 99-115.

44. N. S. Miller, M. S. Gold, J. C. Mahler, "Violent behaviors associated with cocaine use possible pharmacological mechanisms," International Journal of Addictions 21, no. 10 (1991): $1077-$ 1088.

45. James A. Inciardi and Anne. E. Pottieger, "Crack-Cocaine use and street crime," Journal of Drug Issues 24, no 1/2 (1994): 273-279.

46. Todd M. Moore and Gregory L. Stuart, "A review of the literature on marijuana and interpersonal violence," Aggression and Violent Behavior 10, no. 2 (2005): 171-192.

47. C. Heather Ashton, "Adverse effects of cannabis and cannabinoids," British Journal of Anaesthesia 83, no. 4 (1999): 637-649.

48. BFS Grenyer, N Solowij, K Barlow, "Cannabis Use is Associated with Greater Psychotic Symptoms and Increased potential Risk of Aggression" Presented at the International Cannabis and Psychosis Conference, Melbourne, February 5-7 (1999).

49. Albert J. Reiss, Jeffrey A. Roth, "Alcohol, other psychoactive drugs and violence," in Albert J. Reiss and Jeffrey A. Roth (eds.), Understanding and preventing violence (Washington, DC: National Academy press, 1993) 182-220.

50. Boles and Miotto (note 36 above).

51. Barry Spunt, Paul Goldstein, Henry Brownstein, and Michael Fendrich, "The Role of Marijuana in Homicide," Substance Use and Misuse 29, no. 2 (1994): 195-213.

52. Reiss and Roth (note 49 above).

53. Moore and Stuart (see note 46 above). 
54. James J. Collins, "Drinking and Violence: an individual offender focus," in Susan E. Martin (ed.), Alcohol and Interpersonal Violence: Fostering multidisciplinary Perspective (Rockville, MD: US Department of Health and Human Services, 1993) 221-236.

55. Reiss and Roth (note 49 above).

56. Alan R. Lang, “Alcohol-Related Violence: Psychological Perspectives,” in Susan E. Martin (ed.), Alcohol and Interpersonal Violence: Fostering multidisciplinary Perspective (Rockville, MD: US Department of Health and Human Services, 1993) 121-147.

57. Boles and Miotto (note 36 above).

49. Elisabeth Schauer and Thomas Elbert, "The Psychological Impact of Child Soldiering," in Erin Martz (ed.), Trauma Rehabilitation After War and Conflict, ed. by Erin Martz, New York: Springer, 2010), 311- 360.

50. Richard Maclure and Myriam Denov, ““I didn't want to die so I joined them”: Structuration and the process of becoming boy soldiers in Sierra Leone," Terrorism and Political Violence 18 (2006): 119-135 (p. 127).

51. International Crisis Group, "DR Congo," http://www.crisisgroup.org/home/index.cfm?id=1174\&l=1 (August 27, 2009).

52. Psychological research has stated that males are especially prone to substance use. See also Stephan T. Chermack, , Andy Grogan-Kaylor, Brian E. Perron, Regan L. Murray, Peter De Chaves, Maureen A. Walton, "Violence among men and women in substance use disorder treatment: A multi-level event-based analysis," Drug and Alcohol Dependence 112, no. 3 (2010): 194200. However, due to the unequal distribution of men and female in our sample, it was not possible to control for this potential confounding factor in the upcoming analysis.

53. Iris-Tatjana, and Thomas Elbert, "Structural and functional neuroplasticity in relation to traumatic stress." Current Directions in Psychological Science 16, no. 6 (2007): 321-325.

54. Richard J. McNally, "Cognitive abnormalities in post-traumatic stress disorder," Trends in Cognitive Sciences 10, no. 6 (2006): 271-277.

55. Tobias Hecker, Katharin Hermenau, Anna Maedl, Harald Hinkel, Maggie Schauer, and Thomas Elbert, "Does Perpetrating Violence Damage Mental Health? Differences between Forcibly Recruited and Voluntary Combatants in DR Congo," Journal of Traumatic Stress 26. doi: $10.1002 /$ jts (2013).

56. Jum C. Nunnaly, Psychometric theory (New York: McGraw-Hill, 1978).

57. Tobias Hecker, Katharin Hermenau, Anna Maedl, Thomas Elbert, and Maggie Schauer, "Appetitive aggression in former combatants - derived from the ongoing conflict in DR Congo." International Journal of Law and Psychiatry 35, no. 3 (2012): 244-249. 
58. Hecker et al., "Perpetrating Violence Damage Mental Health” (see note 55 above).

59. Hecker et al., "Appetitive aggression in former combatants" (see note 57 above).

60. Rachel Brett and Irma Specht, Young soldiers: Why they choose to fight (Colorado: Lynne Rienner, 2004).

61. Redress, Victims, perpetrators or heroes? Child soldiers before the international criminal court (London: The Redress Trust, Seeking Reparation for Torture Survivors, 2006).

62. Schauer and Elbert (see note 49 above), 316.

63. Ibid., 319.

64. Anselm Crombach, Roland Weierstall, Tobias Hecker, Inga Schalinski, and Thomas Elbert, "Social status and the desire to resort to violence - a study on former child soldiers of Uganda." Journal of Aggression, Maltreatment and Trauma (in press; 2013).

65. Hans Romkema, Opportunities and Constraints for the Disarmament \& Repatriation of foreign armed groups in the Democratic Republic of Congo. The Cases of the FDLR, FNL, and ADF/NALU. Washington: The World Bank, 2007), p. 30.

66. Jens C. Andvig and Scott Gates, "Recruiting Children for Armed Conflict." In Scott Gates and Simon Reich (eds.), Child Soldiers in the Age of Fractured States, (Pittsburgh: University of Pittsburgh, 2009), 77-91.

67. Daya Somasundaram, "Child soldiers: understanding the context," BMJ 324, no. 7348 (2002): 1268-1271.

68. Hecker et al. "Perpetrating Violence Damage Mental Health" (see note 55 above).

69. Jocelyn Kelly, Rape in War: Motives of Militia in DRC, (Washington: United States Institute of Peace, 2010).

70. Romkema (see note 65 above). 
Tables and Figures

Table 1. Descriptive statistics

\begin{tabular}{llllll}
\hline Variable & Mean & Std. & Min & Max & Obs. \\
\hline Perpetrated violence & 3.87 & 1.84 & 0 & 7 & 217 \\
Alcohol use & 0.53 & 0.50 & 0 & 1 & 223 \\
Alcohol functioning & 0.18 & 0.39 & 0 & 1 & 222 \\
Drug use & 0.17 & 0.38 & 0 & 1 & 223 \\
Drug functioning & 0.82 & 0.39 & 0 & 1 & 94 \\
Recruitment & 0.49 & 0.50 & 0 & 1 & 220 \\
Age joined & 16.83 & 5.89 & 0 & 37 & 224 \\
Duration & 6.54 & 5.26 & 0.04 & 28 & 224 \\
No. of armed groups & 1.52 & 0.79 & 1 & 5 & 224 \\
Military rank & 2.84 & 1.82 & 1 & 8 & 212 \\
FDLR & 0.52 & 0.59 & 0 & 2 & 224 \\
\hline
\end{tabular}


Table 2. Alcohol usage and perpetrated violence

\begin{tabular}{|c|c|c|c|c|c|}
\hline Variable & Model 1 & Model 2 & Model 3 & Model 4 & Full \\
\hline \multirow[t]{2}{*}{ Constant } & $4.781 * * *$ & $4.929 * * *$ & $4.674 * * *$ & $4.807 * * *$ & $5.147 * * *$ \\
\hline & $(0.419)$ & $(0.413)$ & $(0.421)$ & $(0.415)$ & $(0.388)$ \\
\hline \multirow[t]{2}{*}{ Alcohol use } & $0.653^{* * *}$ & & $0.629 * * *$ & & \\
\hline & $(0.218)$ & & $(0.217)$ & & \\
\hline \multirow[t]{2}{*}{ Alcohol functioning } & & $0.735^{* * *}$ & & $0.716^{* * *}$ & $0.730 * * *$ \\
\hline & & $(0.276)$ & & $(0.275)$ & $(0.277)$ \\
\hline \multirow[t]{2}{*}{ Age joined } & $-0.103^{* * *}$ & $-0.102^{* * *}$ & $-0.106^{* * *}$ & $-0.106^{* * *}$ & $-0.103^{* * *}$ \\
\hline & $(0.019)$ & $(0.019)$ & $(0.019)$ & $(0.019)$ & $(0.019)$ \\
\hline \multirow[t]{2}{*}{ Duration } & $-0.050 * *$ & $-0.050 * *$ & $-0.070 * * *$ & $-0.071 * * *$ & $-0.043^{* *}$ \\
\hline & $(0.022)$ & $(0.022)$ & $(0.024)$ & $(0.024)$ & $(0.021)$ \\
\hline \multirow[t]{2}{*}{ No. of armed groups } & 0.204 & 0.219 & 0.169 & 0.180 & \\
\hline & $(0.143)$ & $(0.144)$ & $(0.144)$ & $(0.144)$ & \\
\hline \multirow[t]{2}{*}{ Military rank } & $0.132^{* * *}$ & $0.157^{* *}$ & $0.177 * *$ & $0.205^{* * *}$ & $0.182^{* * *}$ \\
\hline & $(0.065)$ & $(0.065)$ & $(0.069)$ & $(0.069)$ & $(0.063)$ \\
\hline \multirow[t]{2}{*}{ Recruitment } & $0.575^{* *}$ & $0.529 * *$ & $0.644 * * *$ & $0.604 * * *$ & $0.558^{* *}$ \\
\hline & $(0.228)$ & $(0.228)$ & $(0.230)$ & $(0.230)$ & $(0.228)$ \\
\hline \multirow[t]{2}{*}{ FDLR } & & & $0.381 *$ & $0.409 *$ & \\
\hline & & & $(0.216)$ & $(0.217)$ & \\
\hline $\mathrm{N}$ & 205 & 204 & 205 & 204 & 204 \\
\hline Adjusted $\mathrm{R}^{2}$ & 0.1913 & 0.1817 & 0.1999 & 0.1922 & 0.1762 \\
\hline
\end{tabular}

Note: Reported are the standardized beta coefficients. Standard errors are in parentheses; *** $\mathrm{p}<0.01,{ }^{* *} \mathrm{p}<0.05, * \mathrm{p}<0.1$ 
Table 3. Drug usage and perpetrated violence

\begin{tabular}{|c|c|c|c|c|c|}
\hline Variable & Model 1 & Model 2 & Model 3 & Model 4 & Full \\
\hline \multirow[t]{2}{*}{ Constant } & $4.832 * * *$ & $5.164 * * *$ & $4.723^{* * *}$ & $4.968^{* * *}$ & $5.061 * * *$ \\
\hline & $(0.417)$ & $(0.820)$ & $(0.419)$ & $(0.797)$ & $(0.393)$ \\
\hline \multirow[t]{2}{*}{ Drug use } & $0.796^{* * *}$ & & $0.765^{* * *}$ & & $0.787 * * *$ \\
\hline & $(0.281)$ & & $(0.280)$ & & $(0.282)$ \\
\hline \multirow[t]{2}{*}{ Drug functioning } & & -0.388 & & -0.615 & \\
\hline & & $(0.442)$ & & $(0.437)$ & \\
\hline \multirow[t]{2}{*}{ Age joined } & $-0.097 * * *$ & $-0.069 * *$ & $-0.100 * * *$ & $-0.077 * *$ & $-0.097 * * *$ \\
\hline & $(0.019)$ & $(0.033)$ & $(0.019)$ & $(0.033)$ & $(0.019)$ \\
\hline \multirow[t]{2}{*}{ Duration } & $-0.052 * *$ & 0.011 & $-0.071 * * *$ & -0.038 & $-0.045^{* *}$ \\
\hline & $(0.022)$ & $(0.041)$ & $(0.024)$ & $(0.044)$ & $(0.021)$ \\
\hline \multirow[t]{2}{*}{ No. of armed groups } & 0.228 & 0.109 & 0.192 & 0.046 & \\
\hline & $(0.143)$ & $(0.229)$ & $(0.144)$ & $(0.223)$ & \\
\hline \multirow[t]{2}{*}{ Military rank } & $0.147 * *$ & 0.114 & $0.192^{* * *}$ & $0.232^{* *}$ & $0.173 * * *$ \\
\hline & $(0.065)$ & $(0.105)$ & $(0.069)$ & $(0.111)$ & $(0.063)$ \\
\hline \multirow[t]{2}{*}{ Recruitment } & $0.548^{* *}$ & 0.355 & $0.619 * * *$ & 0.528 & $0.579 * *$ \\
\hline & $(0.227)$ & $(0.369)$ & $(0.230)$ & $(0.363)$ & $(0.227)$ \\
\hline \multirow[t]{2}{*}{ FDLR } & & & $0.383^{*}$ & $.986^{* *}$ & \\
\hline & & & $(0.216)$ & $(0.383)$ & \\
\hline $\mathrm{N}$ & 205 & 91 & 205 & 91 & 205 \\
\hline Adjusted $\mathrm{R}^{2}$ & 0.1876 & 0.0533 & 0.1962 & 0.1126 & 0.1813 \\
\hline
\end{tabular}

Note: Reported are the standardized beta coefficients. Standard errors are in parentheses; *** $\mathrm{p}<0.01,{ }^{* *} \mathrm{p}<0.05, * \mathrm{p}<0.1$ 
Figures

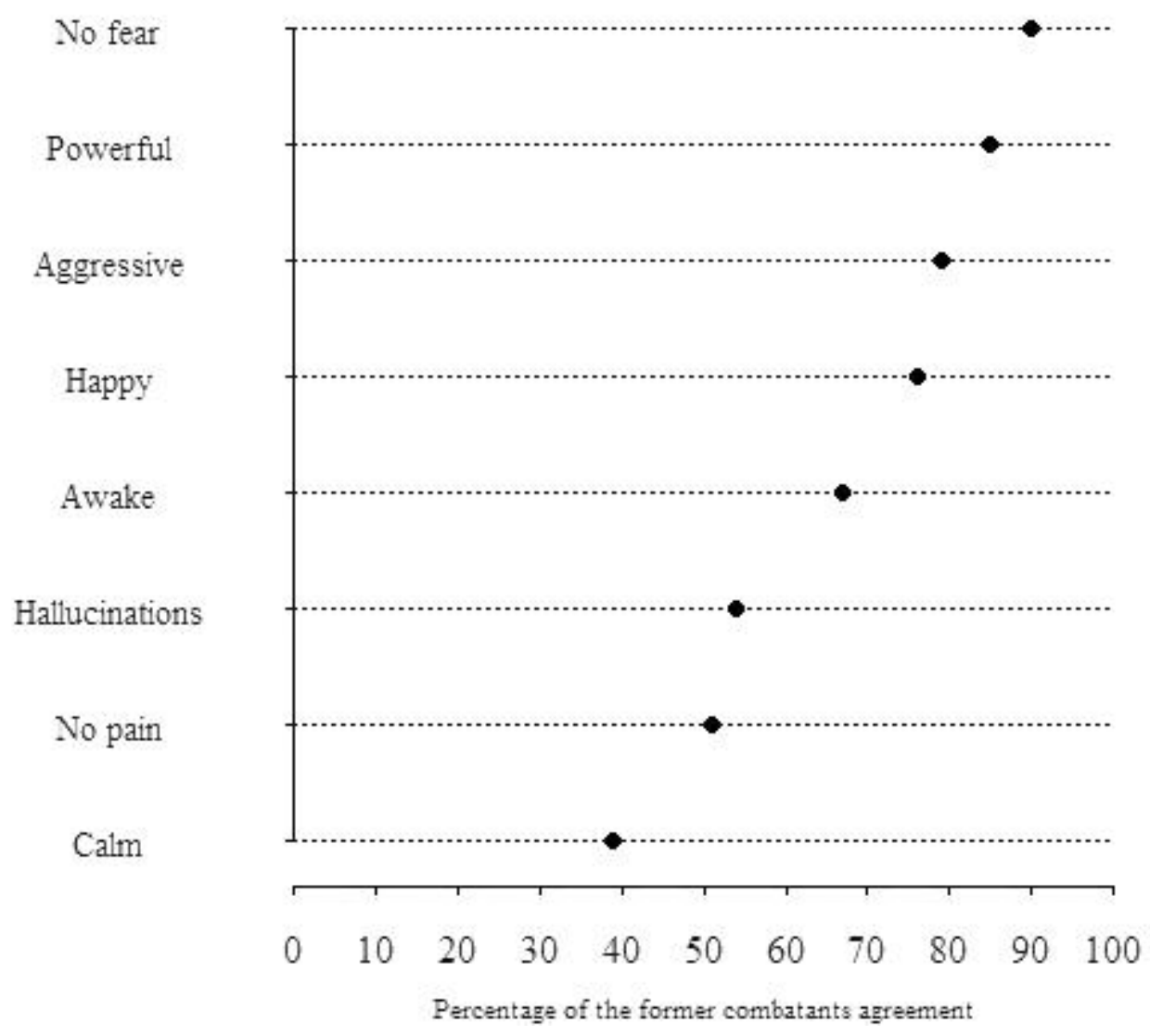

Figure 1: The effect of drugs according to the former combatants 


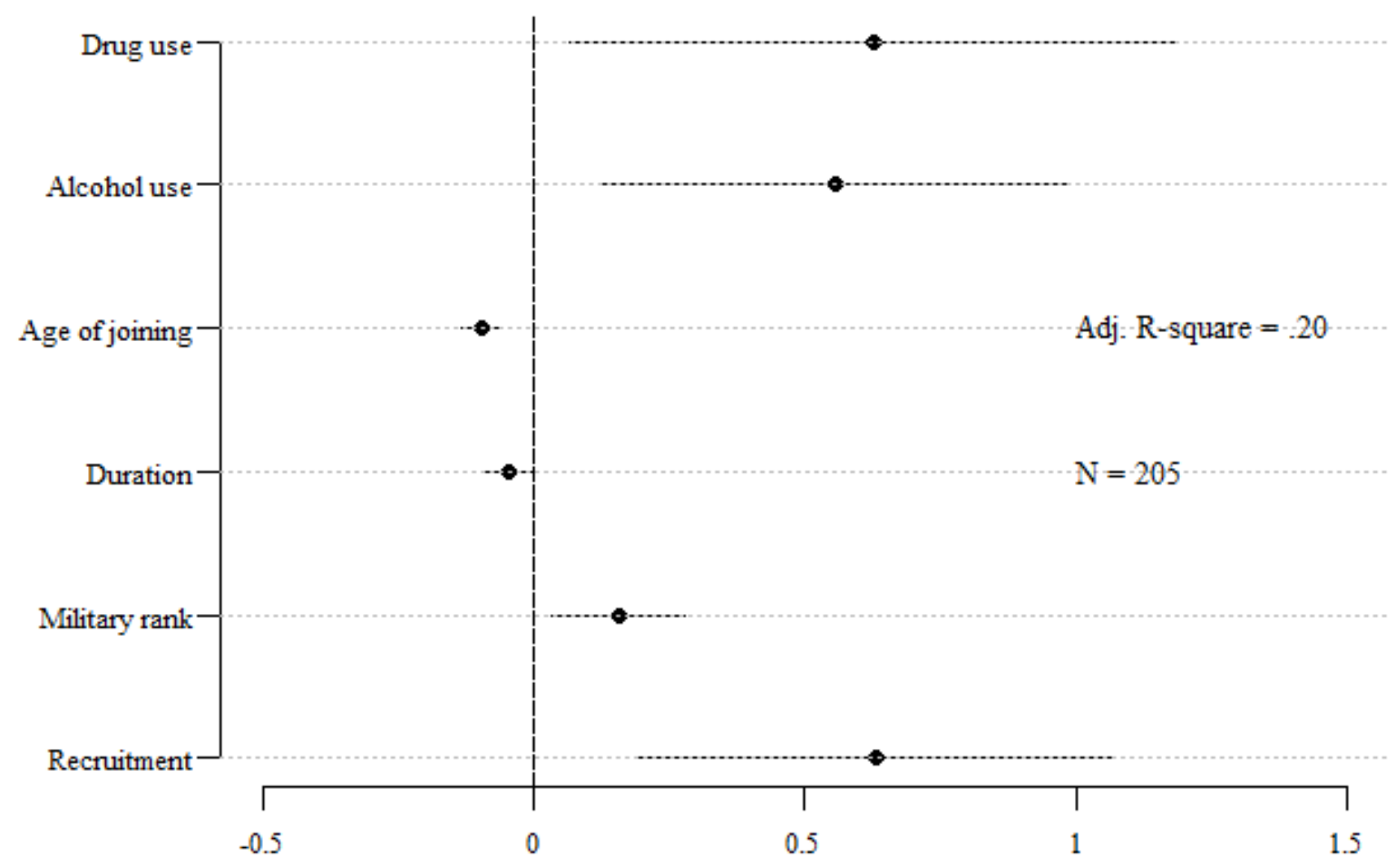

Figure 2: Dot plot of full model

Note: presented are the standardized regression coefficients plotted against the $95 \%$ confidence interval 